\title{
Specialist training in orthodontics: experiences of beginning and end
}

\author{
Farooq Ahmed, MFDS RCSEd; Christine Taylor, IMOrth RCS Eng
}

This article aims to update the reader with the latest changes to recruitment for specialist orthodontic training and recounts the experiences of two consecutive trainees (2009-2012 and 2012-ongoing) whose district hospital is Royal Lancaster Infirmary (RLI). Firstly, Farooq Ahmed tells of his experience as national recruitment was introduced in 20I2, and of his first months as a specialist trainee. Christine Taylor then tells of her final year as a trainee and the first steps into her working life as a specialist in orthodontics.

\section{INTRODUCTION}

Orthodontics: the branch of dentistry concerned with growth of the teeth, jaws and face.

Although orthodontic treatment can be carried out by any dentist who feels competent to do so, only those on the specialist register regulated by the General Dental Council (GDC) can call themselves a specialist orthodontist. To become a specialist in orthodontics, a dentist needs to undertake specialist training on an approved national course. To be accepted onto this course, they will usually have passed the Membership of the Joint Dental Faculties of the Royal College of Surgeons of England (MJDF) or equivalent. This is taken after the completion of the two-year foundation programme once the initial dental qualification has been achieved. The course is very competitive; therefore, to gain entry, the candidate will have a well-rounded curriculum vitae (see figure I).

\begin{tabular}{|c|c|}
\hline \multicolumn{2}{|c|}{ Person Specification } \\
\hline Essential & Desirable \\
\hline $\begin{array}{l}\text { Registered with GDC } \\
\text { BDS (or equivalent) } \\
\text { MIDF (or equivalent) } \\
24 \text { months post-primary } \\
\quad \text { qualification }\end{array}$ & \\
\hline $\begin{array}{l}\text { Clinical skills } \\
\text { Research experience } \\
\text { Clinical governance } \\
\text { CPD } \\
\text { Communication skills } \\
\text { Management and leadership } \\
\quad \text { experience } \\
\text { Personal skills }\end{array}$ & Teaching experience \\
\hline \multicolumn{2}{|c|}{ Figure I Person specification details } \\
\hline
\end{tabular}

\section{RECRUITMENT}

National recruitment for specialist training has been a relatively recent phenomenon. August 2007 was the first national attempt at medical specialist recruitment, part of the modernising medical careers reformation. The overall aims were 'to reform this phase of postgraduate training in particular and to streamline postgraduate medical training.'(I) Local recruitment had been shown to have inherent problems, the main factor being the potential for unfair recruitment. ${ }^{(2)}$ From a candidacy perspective, repeated interviews and absences from employment created extra hurdles at an already stressful point early in career development. Medical national recruitment boasted positive feedback from candidates and showed improvement year-on-year.(2) Currently, over 95\% of medical recruitment takes place via national recruitment. ${ }^{(3)}$

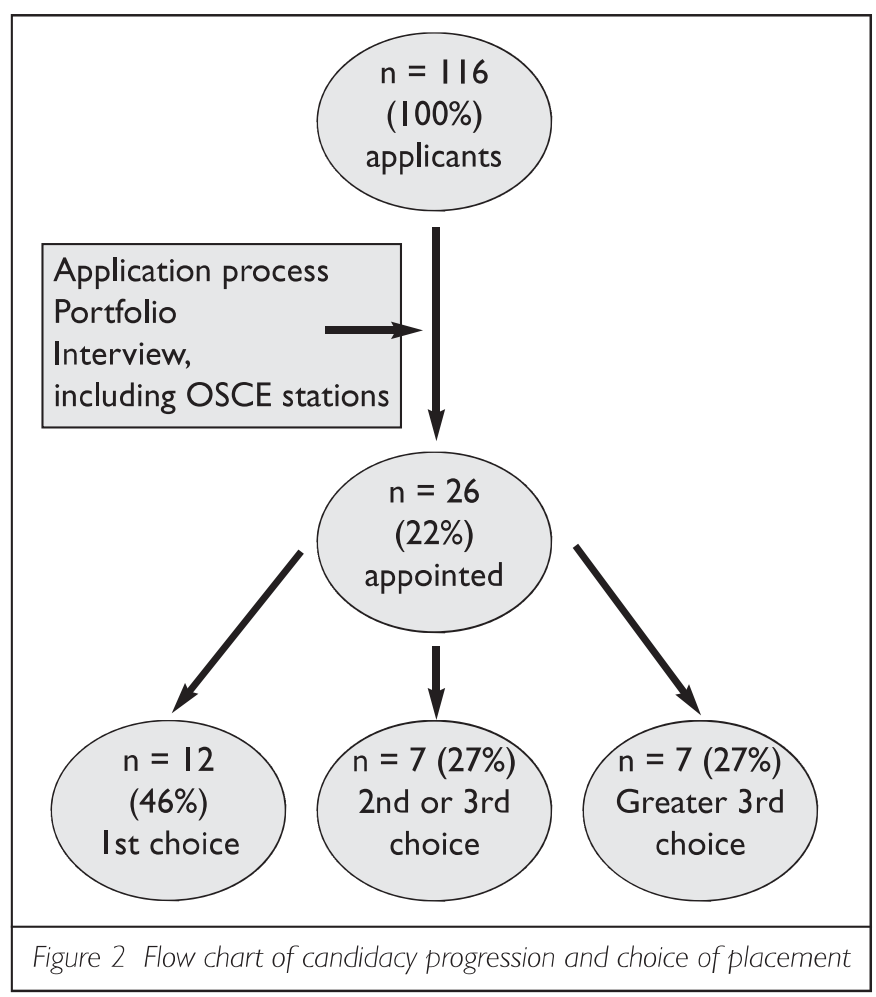

In 201 I, national dental recruitment was carried out at a foundation level (DFI). A 100\% fill rate was achieved and $45 \%$ of candidates received their first preference of regional scheme. The Department of Health was keen to roll out national recruitment to speciality training within dentistry. In 2012, the Committee of Postgraduate Dental Deans (COPDENT) agreed to pilot national recruitment for speciality training in orthodontics. It was decided the London Deanery would coordinate the national process. The interviews were held on 10-II May 2012. 


\section{FAROOQ AHMED'S EXPERIENCE}

\section{Experience of national recruitment}

My journey (see figure 2) through the national recruitment process began with a structured application process. Traditional details of employment and references were coupled with questions exploring my experiences in dentistry, audit and management, academic achievements, personal skills and commitment to orthodontics. Notice of invitation to interview was given only two weeks beforehand and included a request for a portfolio displaying:

- qualifications

- clinical experience

- career progression

- publications

- audits and posters

- academic achievements, and

- continued professional development in the last five years

This created a busy two weeks, to say the least! My interview for the national orthodontic recruitment was held in May 2012. I was one of the first candidates to experience the process. There were six stations, including scenarios which tested communicating with a patient played by an actor and written stations. The duration of the interview was approximately two hours. When the bell rang for the end, relief appeared like a long-lost friend!

The process had saved me countless hours of preparing for each individual institution, had local recruitment still been in place. However, it also meant that my first interview was my final one. In addition to my abilities being tested, I indicated my own preferred options for where I wanted to be placed. This appeared to be a leap of faith at the time, but I received one of my highest-ranked choices in Lancaster and Manchester.

\section{Experience of orthodontic training}

My three-year training began in October 2012. The post is split between two locations, Royal Lancaster Infirmary (RLI) and University Dental Hospital of Manchester (UDHM). It has been so designed for the trainee to gain experience in a district general hospital (RLI) and a teaching hospital (UDHM). My typical week involves spending the first two days at Lancaster, so I generally stay overnight. On Wednesday, I am back in Manchester with journal club at 8.30am, at which an article will be reviewed in turn by the orthodontic registrars. It may be a classic paper or the latest research in our field. The morning is then spent being taught as a joint group of first and second years. In the afternoon, laboratory sessions are scheduled to explore different mechanisms of orthodontic procedures. Thursday is a research day dedicated to my MSc and academic study. Friday is another clinical day, this time at the UDHM. I am supervised by different consultants in the morning and afternoon, which gives me the advantage of learning from different clinicians (see figure 3).

Due to the highly specialised nature of the field, I had little hands-on experience in orthodontics from my undergraduate training, as it is mainly within the sphere of postgraduate education. On starting in post, one of the first procedures I carried out was the placement of brackets onto teeth. A simple notion perhaps! However, after being acquainted with the background theory, it became apparent that it is a highly demanding technical procedure. I would equate my initial attempt to my first driving lesson, exhausting and intense.

Challenges faced on starting orthodontic speciality training The key challenge I have faced so far has been time management. As well as my clinical and academic commitments, I am required to register for a master's degree with the University of Manchester. The topic for my MSc is investigating the level of supervision and scope of practice of orthodontic therapists. Balancing my time between clinical and academic learning has been challenging. Another part of being at middle-grade level involved taking on managerial and administrative roles, such as conducting audits, attending departmental meetings, producing timetables and giving presentations at journal club and audit meetings.

\begin{tabular}{|c|c|c|l|l|c|}
\hline $\begin{array}{c}\text { Ist-year } \\
\text { timetable }\end{array}$ & Monday & Tuesday & Wednesday & Thursday & Friday \\
\hline AM & $\begin{array}{c}\text { New } \\
\text { patient } \\
\text { clinic }\end{array}$ & $\begin{array}{c}\text { Treatment } \\
\text { clinic }\end{array}$ & $\begin{array}{c}\text { Journal club } \\
\text { Teaching }\end{array}$ & Research & $\begin{array}{c}\text { Treatment } \\
\text { clinic }\end{array}$ \\
\hline PM & $\begin{array}{c}\text { Treatment } \\
\text { clinic }\end{array}$ & $\begin{array}{c}\text { Treatment } \\
\text { clinic }\end{array}$ & Laboratory & Research & $\begin{array}{c}\text { Treatment } \\
\text { clinic }\end{array}$ \\
\hline Location & Lancaster & Lancaster & Manchester & & Manchester \\
\hline Figure 3 Weekly timetable for year one of speciality orthodontic training \\
\hline
\end{tabular}

My district unit at Lancaster has one consultant, an associate specialist and a speciality doctor. This contrasts to UDHM which caters for over ten orthodontic consultants, three postCSST posts and many more registrars. Through this post, I therefore get the opportunity to work in a small team in Lancaster and experience being part of a much larger group at UDHM. Both units provide multidisciplinary care with orthognathic and hypodontia cases.

\section{CHRISTINE TAYLOR'S EXPERIENCE}

Christine Taylor will now cover the final year, the examinations and career opportunities.

\section{Experience of final exams}

The culmination of the three-year specialist training was two-fold. Firstly, to meet the requirements of the master's degree at the University of Manchester, and secondly, to gain the Intercollegiate Specialty Diploma of Membership in Orthodontics (IMOrth) at one of the Royal Colleges in London or Glasgow. ${ }^{(4)}$ In readiness for this, consultants, postCSSTs and fellow students helped prepare the candidates for the coming final examinations. Exam techniques were practised and knowledge tested.

In Manchester, the master's degree was tested throughout by way of end-of-year examinations over the three years. The final third-year examination involved the presentation of two treated cases, a viva voce and the assessment of treatmentplanning skills with an unseen case.

I attended the IMOrth examinations in London. This examination was run over three days. It involved the presentation of five cases personally treated during the three-year course, with two being tested in detail. Two objective structured clinical examinations (OSCE) and finally, two sessions in structured clinical reasoning (SCRC). 
The preparation of the five cases was most time consuming, with all being treated and displayed to an extremely high standard. These not only tested the practicalities of the treatment provided but also the clinical management skills of the candidate. They were composed of plaster models, photographs and a folder with a written record.

The pre- and post-treatment plaster models were trimmed carefully to accurately depict the occlusion. Extra-oral and intra-oral photographs were presented which had been taken before, during key stages and after treatment. The folder described the patient, the malocclusion, diagnosis and treatment, including the rationale of treatment, and finally, a reflection on the result and the prognosis for stability.

The folders and model boxes filled a suitcase almost by themselves! On arrival at the Royal College, the five cases were handed in, having been transported with great care on the journey and never being allowed to get out of one's sight. There is a cautionary tale of how one candidate travelled by plane and the suitcase with the models went missing. The plaster study models should also be thoroughly checked when collected from the laboratory. When sitting a different examination, I found the models didn't quite sit flat to the table, but only once I had already travelled to London! After racing around with only a half hour to spare before the shops closed, I found an ironmonger and purchased several grades of sandpaper. An evening was then spent adjusting the models and trying to clean the bathroom of a light dusting of white powder, which, if seen, could have been open to misinterpretation! Once handed over, the models are not seen again until they have been judged. Two cases were chosen, by the examiners, for the candidate to be examined on in detail. The candidate being asked to defend and justify the management options and to discuss any alternative treatment plans.

The OSCE involved I 3 stations, where practical skills and knowledge were tested. These included tracing radiographs, designing appliances, labelling pictures of equipment and drawing graphs of the properties of different metal alloys. Some of the stations had actors, who were brilliant at being either patients or concerned parents with many, many questions. These answers demonstrated not only knowledge but also communication skills. The actors awarded some of the points themselves. All of the stations were supervised and rest stations were included.

For the SCRC, ten minutes was allowed for the candidate to view an unseen case, which was presented as a brief medical/ dental history, plaster study models, extra-oral and intra-oral photographs and radiographs. A pair of examiners then entered the room to hear a summary of the features of the case, followed by the proposed treatment plan, a discussion of the intended treatment mechanics and any alternative treatment options.

Once the exam was over, the candidates waited nervously in the library of the Royal College whilst the examiners' meeting took place. A representative of the examiners then entered the room and read out the numbers of the successful candidates. Thankfully, my number was called. Whilst feedback was available for unsuccessful entrants, those who passed were invited to meet the examiners to enjoy a drink and some nibbles.
Overall, the three years saw the development of skills beyond exam technique and the rigorous testing of scientific knowledge. These included presentation skills, communication techniques and increased confidence in dealing with patients, parents and liaising with colleagues.

\section{Working as a specialist orthodontist}

Once the examinations have been passed, the successful candidates gain a Certificate of Completion of Specialist Training (CSST) and can apply for entry to the specialist list with the General Dental Council.(5)

The career options for the specialist orthodontist include to undertake further study or to commence work as a specialist. The consultant route generally involves training for a further two years and taking the FDS Orth examination to become a hospital consultant. This can also be combined with a university career leading to a professorship.

Working as a specialist within the National Health Service in practice can be as a salaried employee or under contract to the Clinical Commissioning Groups (CCG) to provide specialist orthodontic services. One could work in private practice or in combination. These days this may be within a corporate body. The Community Dental Service also provides career opportunities.

The specialist receives referrals from primary dental care or via the consultant hospital services.

I am combining what I hope will be the best of both worlds. I have a post as an associate specialist two days a week here at RLI and I am also working in specialist practice. I enjoy the variety of two different environments and all the challenges that working with patients brings. I look forward to the opportunities that the next few years bring ...

\section{REFERENCES}

I. Medical Schools Council. Response from the Medical Schools Council to the MMC Inquiry. 2007. Available at: http://www.mmcinquiry.org.uk/MMC_InquiryReportREVD3.pdf

2. Irish B, Carr A, Sowden D, Douglas N, Patterson F. Recruitment into specialty training in the UK. BMJ Careers, 12 January 2011

3. Cook $\mathrm{P}$, Jones E. National recruitment in dentistry: the orthodontic experience. J Orthod. 2012 Sep;39(3): 145-6 doi: | 0.1 | 79/| 4653 | 25 | 2Z.00000000030

4. Royal College of Surgeons of England. Regulations and guidelines for the Intercollegiate Speciality Diploma of Membership In Orthodontics. Available at: http://www.rcseng.ac.uk/exams/dental/morth

5. General Dental Council. Specialist lists. Available at: http://www.gdc-uk.org/Dentalprofessionals/Specialistlist/ Pages/default.aspx 